\title{
Exploring the Factors Affecting Consumer Acceptance of Proximity M-Payment Services
}

\author{
Apostolos Giovanis ${ }^{1}$, Androniki Kavoura ${ }^{1}$, Ioannis Rizomyliotis ${ }^{2}$, Sotiris Varelas ${ }^{3}$ and \\ Aspasia Vlachvei ${ }^{4}$ \\ ${ }^{1}$ University of West Attica, Ag.Spiridonos, 12210, Athens, Greece \\ ${ }^{2}$ University of Brighton,Mithras House, Lewes Road, Brighton BN2 4AT, UK \\ ${ }^{3}$ Neapolis University of Pafos, 2 Danais Av., 8042, Paphos, Cyprus \\ ${ }^{4}$ Western Macedonia University of Applied Sciences, 52100, Kastoria, Greece \\ agiovaniseuniwa.gr
}

\begin{abstract}
The purpose of this study is to analyze the factors determining consumers' intentions to adopt NFC proximity mobile payment services ( $\mathrm{p}$-mps). An extended version of the Unified Theory of Acceptance and Use of Technology (UTAUT), a model that incorporates the most relevant theoretical approaches in the adoption literature was selected to investigate the consumers' adoption process. To empirically test the proposed model, data were collected from 513 consumers of mobile internet service providers in Greece and were analyzed using PLS. The results indicated that p-mps features, expressed by consumers' expectations about service performance and required efforts, along with the social context effects have the biggest impact on consumers' intentions to use the service, followed by channel characteristics, reflecting consumers' beliefs about p-mps usage risk and trust. Potential customers' characteristics moderating analysis suggested that the effects of performance expectancy and perceived trust on behavioral intentions are affected by gender, age and previous experience, while that of social influence only by potential customers' previous experience. Theoretical and managerial implications, limitations and suggestions for further research are provided at the end of the study.
\end{abstract}

Keywords: M-payment, NFC p-mps adoption, UTAUT, Risk, Trust, Individual Differences, Marketing Financial Self-service Technologies.

\section{Introduction}

Mobile payment system (mps) is an emergent self-service technology (SST) offering payment services through mobile devices without locational and temporal restrictions [1], [2]. According to Gerpott and Meinert [3], there are two categories of mps: a) Remote mps (hereafter $\mathrm{r}-\mathrm{mps}$ ), enabling payments through mobile telecommunication or Wi-Fi networks, and allow the payments for digital content or online purchases through SMS or mobile internet connection, b) Proximity mps (hereafter p-mps), enabling payments through short-range communication technologies and allow for payments for purchases such as ticketing, vending, and point-of-sale items, employing 
a QRcode displayed on the smartphone, or a NFC (Near Field Communication) device or Bluetooth low energy (BLE) proximity sensing technology [3], [4]. This study focuses on NFC-enabled p-mps that has become important part of consumers' shopping experience due to the continuous advancements of the technology [3].

The study of the p-mps adoption and usage process has attracted significant attention from academics and practitioners over the last years. Yet consumers' adoption and usage of this m-service is characterized as a complex process due to interplay of many factors that are under-researched so far [2]. According to Adapa and Roy [5] and Frimpong et al. [6] there are technology-, social-, channel- and personal-related factors affecting consumer behavior towards SSTs usage intentions. Although, there are many studies that have used different well-known theoretical frameworks to investigate the adoption of $\mathrm{p}$-mps, there aren't studies that have examined the interplay of all the aforementioned groups of factors in order to better understand the potential customers' decision making process, towards p-mps usage.

Thus, the purpose of this study is to identify the factors affecting the p-mps adoption process and the degree of influence of each factor leading p-mps usage intentions. Drawing on the studies of Adapa and Roy [5] and Frimpong et al. [6], four groups of innovation adoption drivers (i.e. innovation features; social context; channel credibility; and personal characteristics) mainly affect SST's usage intentions. Thus, the proposed modelling framework extends the UTAUT, proposed by Venkatesh et al. [7] and its constructs express the effects of technology-related and social-related factors, with potential users' perceived risk and trust, expressing the role of channelrelated factors, and potential users' demographics in order to better predict the p-mps adoption intentions.

\section{Literature Review and Proposed Model}

There are several theoretical models which have been used to explain the adoption of SSTs. These models include the Technology Acceptance Model (TAM), the Theory of Planned Behavior (TPB), the Innovation Diffusion Theory (IDT), and the Unified Theory of Acceptance and Use of Technology Model (UTAUT) [4], [8], [10]. Focusing on the p-mps context, the majority of the adoption studies use and support the TAM [11] and its extensions as a theoretical framework [12], [13], [14], [15], [16], [17]. Despite the fact that the TAM and its extensions provide a reliable and valid modelling framework to investigate the technology adoption process, it has received a lot of criticism about its predictive ability for two reasons: Firstly, it considering two consumers' salient beliefs related to innovation's attributes (i.e. perceived usefulness and perceived ease of use), and no other external factors that might affect consumers' behavior; Secondly, it assuming that usage is volitional without constraints [7], [9].

To address these limitations Venkatesh et al. [7] proposed the UTAUT which integrates eight well established innovation adoption theoretical frameworks. The UTAUT includes three key constructs: performance expectancy (PE), effort expectancy (EE), social influence (SI) to model behavioral intentions (BI). The latter along with facilitating conditions (FC) predicts also usage behavior. These determinants are 
defined as follows [7, p.447-453]: PE refers to "the degree to which a potential adopter has the opinion that the innovation adoption will help him to improve the performance of a task or work". EE refers to "the degree of ease associated with use of the innovation". SI is defined "as the degree to which an individual perceives that important others believe he or she should use the innovation" and reflects the normative drivers of the innovation adoption process. Finally, FC is defined as "the degree to which an individual believes that an organizational and technical infrastructure exists to support use of the system" (TPB, DTPB).

The original UTAUT considers that PE, EE, and SI are antecedents of BI, while $\mathrm{BI}$ and FC are drivers of potential customers' actual behavior. Hence, this model assumes that the concept of "BI captures the motivational factors that affect the potential adopters' behavior and reflects the effort that they are willing to undertake in order to develop an action" [18]. This study does not consider the FC, as it investigates only potential consumers' intentions to adopt $\mathrm{p}$-mps and not their actual behavior. These three variables represent the technology- and social-related variables motivating consumers to use an SST. Focusing in the context of p-mps there are three studies using UTAUT to investigate the adoption process in Malaysia, UK and USA [9], [19], [20]. All three studies support the significance of PE and BI, two of them found a significant effect of SI on BI [9], [20], and only one confirms the significance of EE on BI [19]. Lately, Slade et al. [8] [9] suggest the extension of UTAUT with perceived risk (PR) and perceived trust (PT) in order to consider the effects of SSTs' channel-related factors in the adoption process. PR in the context of SSTs expresses "the potential for loss in the pursuit of a desired outcome of using the service" [21, p.453]. PT, on the other hand, refers to potential customers' subjective belief that a service provider will fulfil its obligations [8]. Consumers often face spatial and temporal separation from their online providers and this makes them more vulnerable to greater risks as they do not have the full control of their action [8], [9]. Thus, trust in $\mathrm{p}$-mps is essential to mitigate the uncertainty of m-payments to motivate the consumer to use it. Many previous studies in the field of $\mathrm{m}$-services in general and mps in particular empirically validate the positive effect of PT and the negative effect of PR on BI. The studies of Slade et al. [8], [9] for example, suggest PR and PT to be included among the significant drivers of mps adoption in the UK. Moreover, the UTAUT posits that the effects of these five constructs on BI are moderated by individual differences such as gender, age, and technology experience [7], [8], [22]. Among the three previous UTAUT studies in the context of p-mps, none of them considers the moderating role of personal factors in the adoption process. Thus, the use of the complete UTAUT is expected to provide a more comprehensive theoretical framework for predicting p-mps usage intentions and, further, better support the development of a differentiated marketing strategy towards the extension of p-mps adoption and usage. Based on the above discussion, PE, EE, SI, PR, and PT are theorized to influence behavioral intention to use a p-mps. Moreover, individual characteristics, such as gender, age, and previous experience are theorized to moderate the five previous direct relationships. Thus following the studies of Venkatesh et al. [7] and Slade et al. [8] it is hypothesized that:

H1: PE directly and positively affects BI 
H2: EE directly and positively affects BI to adopt p-mps

H3: SI directly and positively affects BI to adopt p-mps

H4: PR directly and negatively affects BI to adopt p-mps

H5: PR directly and positively affects BI to adopt p-mps

H6: a) Gender, b) age and c) experience moderate the positive effect of PE on BI to adopt $\mathrm{p}$-mps, such that the effect will be stronger for younger males with high levels of technology experience

H7: a) Gender, b) age and c) experience moderate the positive effect of EE on BI to adopt p-mps, such that the effect will be stronger for older females with low levels of technology experience

H8: a) Gender, b) age and c) experience moderate the positive effect of SI on BI to adopt p-mps, such that the effect will be stronger for older males with low levels of technology experience

H9: a) Gender, b) age and c) experience moderate the positive effect of PT on BI to adopt $\mathrm{p}$-mps, such that the effect will be stronger for older females with limited experience of the technology

H10: a) Gender, b) age and c) experience moderate the negative effect of PR on BI to adopt p-mps, such that the effect will be stronger for older females with limited experience of the technology

\section{$3 \quad$ Research Methodology}

To ensure the content validity of the scales used to measure the constructs of the proposed models, validated scale items from prior studies were used. As such, the scales proposed by Venkatesh et al. [22] were used to measure PE, EE, SI and BI, while those include in the study of Slade et al. [9] were used to measure PR and PT. All scale items were measured using a 7-point Likert scale with 1 corresponding to "strongly disagree" and 7 to "strongly agree". A conclusive research design was selected in order to examine the relationships described in the conceptual framework. A convenience sampling was employed and a questionnaire was developed and distributed to 600 individuals. This procedure resulted in 530 questionnaires. After eliminating those with unanswered items 513 questionnaires were coded for data analysis. The method of partial least squares (PLS) path methodology [23], an implementation of structural equation modeling (SEM) with Smart PLS 2.0 M3 [24], was used to examine the model and test the proposed hypotheses.

\section{$4 \quad$ Results}

Among the 513 survey participants $59.1 \%$ were male. In terms of age $29.6 \%$ were less than 24 years old; $30.6 \%$ were in the $25-34$ age group; $19.1 \%$ were in the $35-44$ age 
group and $20.7 \%$ were more than 45 years old. In terms of educational background $52 \%$ of the respondents have college degree or higher. The test of the measurement model involves the estimation of reliability; convergent validity, and discriminant validity of the extended UTAUT's constructs, indicating the strength of measures used to test the proposed model [23]. As shown in Table 1, all measures present high item reliability as all corresponding loadings values exceeds the cut-off value of 0.70 . Composite Reliability (CR) values of all measures included in the study exceed 0.93 suggesting that all measures were good indicators of their respective components. Average Variance Extracted (AVE) values for all constructs exceed 0.77, higher than the recommended cut-off value of 0.50 [23] suggesting satisfactory convergent validity. Finally, the square roots of AVE for all first-order constructs, provided in the diagonal of the table, are higher than their shared variances providing strong evidence of discriminant validity among all first order constructs [23].

Table 1. Measurement model assessment.

\begin{tabular}{lccccccccc}
\hline \multicolumn{1}{c}{ LV } & Loadings & AVE & CR & PE & EE & SI & PR & PT & ITU \\
\hline PE & {$[0.85-0.90]$} & 0.77 & 0.91 & $\mathbf{0 . 8 8}$ & & & & & \\
EE & {$[0.86-0.97]$} & 0.80 & 0.95 & 0.57 & $\mathbf{0 . 8 9}$ & & & & \\
SI & {$[0.93-0.97]$} & 0.91 & 0.97 & 0.45 & 0.30 & $\mathbf{0 . 9 5}$ & & & \\
PR & {$[0.88-0.93]$} & 0.81 & 0.95 & -0.35 & -0.32 & -0.25 & $\mathbf{0 . 9 0}$ & & \\
PT & {$[0.83-0.96]$} & 0.82 & 0.93 & 0.51 & 0.41 & 0.47 & -0.49 & $\mathbf{0 . 9 1}$ & \\
ITU & {$[0.97-0.98]$} & 0.95 & 0.98 & 0.66 & 0.56 & 0.52 & -0.48 & 0.59 & $\mathbf{0 . 9 7}$ \\
\hline
\end{tabular}

The PLS-PM method was also used to confirm the hypothesized relationships between the constructs in the proposed model. The significance of the paths included into the proposed model was tested using a bootstrap resample procedure. In assessing the PLS model, the squared multiple correlations $\left(\mathrm{R}^{2}\right)$ of the endogenous latent variable was initially examined and the significance of the structural paths was evaluated [23], [24]. The data analysis for the main effects model, depicted in Table 2(a), indicates that all six hypotheses concerning the direct effects were confirmed. Significant positive relationships were yielded between PE and BI (confirming H1: $\beta=0.31$ ), EE and BI (confirming H2: $\beta=0.20$ ), SI and BI (confirming H3: $\beta=0.20$ ), and PT and BI (confirming H5: $\beta=0.17$ ). Significant negative relationships were observed between PR and BI (confirming H4: $\beta=-0.17$ ). The five significant constructs explained $60 \%$ of variance in BI. Multi-group analysis [25] was used to investigate the moderating effects of individual differences on the relationships between adoption drivers and potential customer BI. As such, the pool sample separated in two groups of respondents according to their gender (male vs. females), age (young: $\leq 30$ yrs. vs. old: $>30$ yrs.) and declared familiarity with m-commerce (high vs. low). As shown in Tables $2 \mathrm{~b}, \mathrm{c}, \mathrm{d}$ the results suggest that gender, age and experience moderate the relationships between PE and BI (confirming H6a, H6b, H6c) and between PT and BI (confirming H9a, H9b, H9c), while experience also moderates the relationship between SI and BI (confirming H8c). 
Table 2. Structural model and moderation analysis results.

\begin{tabular}{lccc}
\hline LV & Value & t-value & Sig. \\
\hline PE & $0.31^{* * *}$ & 6.01 & 0.000 \\
EE & $0.20^{* * *}$ & 8.03 & 0.000 \\
SI & $0.20^{* * *}$ & 5.73 & 0.000 \\
PR & $-0.17^{* * *}$ & -5.29 & 0.000 \\
PT & $0.17^{* * *}$ & 4.58 & 0.000 \\
R $^{2}$ & 0.60 & & \\
\hline
\end{tabular}

(a) Direct effects (pool sample)

\begin{tabular}{lccc}
\hline LV & Male & Female & p-value \\
\hline PE & $0.35^{* * *}$ & $0.24^{* * *}$ & $\mathbf{0 . 0 0 6}$ \\
EE & $0.19^{* * *}$ & $0.18^{* * *}$ & 0.673 \\
SI & $0.20^{* * *}$ & $0.20^{* * *}$ & 0.885 \\
PR & $-0.20^{* * *}$ & $-0.16^{* * *}$ & 0.282 \\
PT & $0.09^{\text {ns }}$ & $0.28^{* * *}$ & $\mathbf{0 . 0 0 0}$ \\
R $^{2}$ & 0.58 & 0.64 & \\
\hline
\end{tabular}

(b) Moderating effects: gender

\begin{tabular}{lccc}
\hline LV & Young & Old & p-value \\
\hline PE & $0.36^{* * *}$ & $0.24^{* * *}$ & $\mathbf{0 . 0 4 9}$ \\
EE & $0.15^{* * *}$ & $0.22^{* * *}$ & 0.207 \\
SI & $0.23^{* * *}$ & $0.15^{* * *}$ & 0.153 \\
PR & $-0.16^{* * *}$ & $-0.19^{* * *}$ & 0.677 \\
PT & $0.09^{* * *}$ & $0.31^{* * *}$ & $\mathbf{0 . 0 0 0}$ \\
$\mathrm{R}^{2}$ & 0.55 & 0.69 & \\
\hline
\end{tabular}

(c) Moderating effects: age

\begin{tabular}{lccc}
\hline \multicolumn{4}{c}{ (b) Moderating effects: gender } \\
\hline LV & High & Low & p-value \\
\hline PE & $0.37^{* * *}$ & $0.19^{* * *}$ & $\mathbf{0 . 0 1 3}$ \\
EE & $0.23^{* * *}$ & $0.14^{* * *}$ & 0.141 \\
SI & $0.11^{* *}$ & $0.30^{* * *}$ & $\mathbf{0 . 0 0 1}$ \\
PR & $-0.15^{* * *}$ & $-0.16^{* * *}$ & 0.825 \\
PT & $0.12^{* *}$ & $0.26^{* * *}$ & $\mathbf{0 . 0 4 9}$ \\
R $^{2}$ & 0.47 & 0.54 & \\
\hline
\end{tabular}

(d) Moderating effects: experience

\section{Discussion}

The purpose of this study was to identify the factors influencing the adoption p-mps, and the degree of influence of each factors leading their usage. An extended version of the UTAUT, investigating the role of technology, social, channel and personal factors of the p-mps adoption intention, was proposed as a ground base for this study. Concurrent with the existing literature of p-mps acceptance [9], [20], the role of PE and EE, reflecting the two technology-related factors, and SI, reflecting the socialrelated factors, in predicting p-mps adoption was confirmed. These results suggest that $\mathrm{p}$-mps service providers aiming to gain competitive advantage and increase the $\mathrm{p}$ mps adoption rates have to offer platforms of great utilitarian value (e.g. speed in task completion, convenience, etc.) which, at the same time, are free of effort and easy to use [9], [19], [22]. Moreover, they have to communicate positive testimonials of satisfied p-mps users which will increase potential consumers' awareness/trial, and educate them. In this research, in accordance with the findings of previous studies [9], [15], [16], PR and PT were also recognized as significant driver and detractor of pmps usage intentions respectively. As such, service providers have to identify the most critical risks that tend to increase customers' fears in using p-mps and, then, select the most appropriate actions to reduce the impact of these threats. This is also expected to raise trust in p-mps transaction security. Finally, the results also confirmed the significant moderating effects of personal factors on consumers' behavior towards p-mps adoption intentions. In accordance with the relevant studies [4], [7], [8], the findings of this study confirmed the significant influence of potential users' differences in the p-mps adoption intention. More specifically, the effect of PE on BI 
seems to be bigger for younger males with high levels of technology experience as this group is more task-oriented. The effects of EE on BI and SI on BI are stronger for older females with low level of technology experience and the effect of SI on BI is stronger for those with low level of technology experience. These results indicate that service providers have to implement a differentiated marketing strategy in order to provide an added value to potential customers with different characteristics which lead to relevant actions efficiency optimization. Future research could be directed towards the consideration of other variables that theoretically affect the adoption mechanism, such as perceived service value, brand reputation and personal traits (i.e. innovativeness, need for control etc.) that could further improve the predicting power of the model within the m-payment services context.

\section{References}

1. Dahlberg T, Guo J, Ondrus J (2015) A critical review of mobile payment research. Electronic Commerce Research and Applications 14: 265-284. doi: 10.1016 /j.elerap.2015.07.006.

2. Oliveira T, Thomas M, Baptista G, Campos F (2016) Mobile payment: understanding the determinants of customer adoption and intention to recommend the technology. Computers in Human Behavior 61: 404-414. doi: 10.1016/k.chb. 2016.03.030.

3. Gerpott TJ, Meinert P (2017) Who signs up for NFC mobile payment services? Mobile network operator subscribers in Germany. Electronic Commerce Research and Applications 23: 1-13. doi: 10.1016/j.elerap.2017.03.002.

4. Slade EL, Williams MD, Dwivedi YK (2013) Mobile payment adoption: classification and review of the extant literature. The Marketing Review 13: 167-190. doi: 10.1362/146934713X13699019904687.

5. Adapa S, Roy SK (2017) Consumers' post-adoption behaviour towards Internet banking: empirical evidence from Australia. Behaviour \& Information Technology, 36: 970-983. doi: 10.1080/0144929X.2017.1319498.

6. Frimpong K, Al-Shuridah O, Wilson A, Sarpong FAA (2017) Effect of inherent innovativeness and consumer readiness on attitudes to mobile banking. Journal of Financial Services Marketing 22: 187-201. doi: 10.1057/s41264-017-0037-2.

7. Venkatesh, V, Morris M G, Davis G B, Davis F D (2003) User acceptance of information technology: toward a unified view. MIS Quarterly 27: 425-478. doi: 10.2307/30036540.

8. Slade EL, Williams MD, Dwivedi Y (2013) Extending UTAUT2 to explore consumer adoption of mobile payments. in Proceedings of UK Academy for Information Systems Conference pp. 36-59.

9. Slade, E., Williams, M., Dwivedi, Y. and Niall Piercy (2015) Exploring consumer adoption of proximity mobile payments, Journal of Strategic Marketing 23: 209-223. doi: 10.1080/0965254X.2014.914075.

10. Blut M, Wang C, Schoefer K (2016) Factors influencing the acceptance of selfservice technologies: a meta-analysis. Journal of Service Research 19: 396-416. doi: $10.1177 / 1094670516662352$. 
11. Davis FD, Bagozzi R P, Warshaw P R (1989) User acceptance of computer technology: a comparison of two theoretical models. Management Science 35: 9821003. doi: $10.1287 / \mathrm{mnsc} .35 .8 .982$.

12. Leong, L.Y., Hew, T.S., Tan, G.W.H. and Ooi, K.B. (2013) Predicting the determinants of the NFC-enabled mobile credit card acceptance: a neural networks approach. Expert Systems with Applications 40: 5604-5620. doi: 10.1016/j.eswa. 2013.04.018.

13. Shin S, Lee WJ (2014) The effects of technology readiness and technology acceptance on NFC mobile payment services in Korea. Journal of Applied Business Research. 30: 1615-1626. doi: 10.19030/jabr.v30i6.8873.

14. Tan GWH, Ooi KB, Chong SC, Hew TS (2014) NFC mobile credit card: the next frontier of mobile payment?, Telematics and Informatics. 31: 292-307. doi: 10.1016/ j.tele.2013.06.002.

15. Ooi, KB, Tan GWH (2016) Mobile technology acceptance model: an investigation using mobile users to explore smartphone credit card. Expert Systems with Applications. 59: 33-46. doi: 10.1016/j.eswa.2016.04.015.

16. Ozturk AB (2016) Customer acceptance of cashless payment systems in the hospitality industry. International Journal of Contemporary Hospitality Management 28: 801-817. doi: 10.1108/IJCHM-02-2015-0073.

17. Liébana-Cabanillas F, Luna IRD, Montoro-Ríos F (2017) Intention to use new mobile payment systems: a comparative analysis of SMS and NFC payments. Economic Research-Ekonomska Istraživanja 30: 892-910. doi: 10.1080/1331677 X.2017.1305784.

18. Ajzen I (1991) The theory of planned behavior, Organizational Behavior and Human Decision Processes 50: 179-211. doi: 10.1016/0749-5978(91)90020-T.

19. Tang CY, Lai C C, Law CW, Liew M C, Phua VV (2014) Examining key determinants of mobile wallet adoption intention in Malaysia: an empirical study using the unified theory of acceptance and use of technology model. International Journal of Modelling in Operations Management. 4: 248-265. doi: 10.1504/IJMOM.2014. 067383.

20. Morosan C, DeFranco A (2016) It's about time: revisiting UTAUT2 to examine consumers' intentions to use NFC mobile payments in hotels. International Journal of Hospitality Management 3: 17-29. doi: 10.1016/j.ijhm.2015.11.003.

21. Featherman M S, Pavlou PA (2003) Predicting e-services adoption: a perceived risk facets perspective. International Journal of Human-Computer Studies. 59: 451-474. doi: 10.1016/S1071-5819(03)00111-3.

22. Venkatesh, V, Thong J Y, Xu X (2012) Consumer acceptance and use of information technology: extending the unified theory of acceptance and use of technology", MIS Quarterly. 36: 157-178. doi: 10.2307/41410412.

23. Hair J F, Ringle CM, Sarstedt M (2011) PLS-SEM: indeed a silver bullet. The Journal of Marketing Theory and Practice 19: 139-152. doi: 10.2753/MTP10696679190202.

24. Ringle, C.M., Wende, S. and Will, A. (2005), SmartPLS 2.0 (M3) Beta, Hamburg, [online] www.smartpls.de (Accessed 5 May 2010).

25. Matthews L (2017) Applying multigroup analysis in PLS-SEM: a step-by-step process. In Latan, H., Noonan, R. (eds.), Partial Least Squares Path Modeling, pp. 219-243. Springer Heidelberg. doi: 10.1007/978-3-319-64069-3_10. 
UNIVERSITY OF WEST ATTICA

\section{CAMPUS 1}

Address : Agiou Spiridonos Str., 122 10, Egaleo, Athens

Tel. : : +30 2105385209

Egaleo: 9/10/2018

E-mail : nkavoura@teiath.gr

TO: -

Dr Apostolos Giovanis

To whom it may concern

This is to certify that the paper titled:

Exploring the Factors Affecting Consumer Acceptance of Proximity MPayment Services

submitted by:

Apostolos Giovanis ${ }^{1}$, Androniki Kavoura ${ }^{1}$, Ioannis Rizomyliotis ${ }^{2}$, Sotiris Varelas ${ }^{3}$ and Aspasia Vlachvei ${ }^{4}$

${ }^{1}$ University of West Attica, Ag.Spiridonos, 12210, Athens, Greece

${ }^{2}$ University of Brighton,Mithras House, Lewes Road, Brighton BN2 4AT, UK

${ }^{3}$ Neapolis University of Pafos, 2 Danais Av., 8042, Paphos, Cyprus

${ }^{4}$ Western Macedonia University of Applied Sciences, 52100, Kastoria, Greece

after double blind review, has been approved for presentation at ICSIMAT

The Work will be published in the book series [Springer Proceedings in Business and Economics].

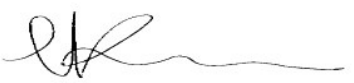




\title{
Consent to Publish for Conference Proceedings
}

Title of Book/Volume/Conference (hereinafter called “Work): Strategic Innovative Marketing and Tourism - 7th ICSIMAT, Athens, Greece, 2018

\author{
Editor(s) name(s) (hereinafter called "Editor"): Prof. Androniki Kavoura, Prof. Efstathios \\ Kefallonitis, Prof. Apostolos Giovanis
}

Title of the conference paper (hereinafter called "Contribution"): Exploring the Factors Affecting Consumer Acceptance of Proximity M-Payment Services

Author(s) full name(s) (hereinafter jointly called “Author”): Apostolos Giovanis, Androniki Kavoura, Ioannis Rizomyliotis, Sotiris Varelas and Aspasia Vlachvei

Corresponding author's name, address, affiliation and e-mail: Apostolos Giovanis, University of West Attica, Ag.Spiridonos, 12210, Athens, Greece, agiovanis@uniwa.gr

When Author is more than one person the expression "Author" as used in this agreement will apply collectively unless otherwise indicated.

The Publisher intends to publish the Work under the imprint Springer. The Work may be published in the book series [Springer Proceedings in Business and Economics].

\section{§ 1 Rights Granted}

Author hereby grants to Springer International Publishing AG (hereinafter called "Publisher") the exclusive, sole, permanent, world-wide, transferable, sub-licensable and unlimited right to reproduce, publish, distribute, transmit, make available or otherwise communicate to the public, translate, publicly perform, archive, store, lease or lend and sell the Contribution or parts thereof individually or together with other works in any language, in all revisions and versions (including soft cover, book club and collected editions, anthologies, advance printing, reprints or print to order, microfilm editions, audiograms and videograms), in all forms and media of expression including in electronic form (including offline and online use, push or pull technologies, use in databases and data networks (e.g. Internet) for display, print and storing on any and all stationary or portable end-user devices, e.g. text readers, audio, video or interactive devices, and for use in multimedia or interactive versions as well as for the display or transmission of the works or parts thereof in data networks or search engines, and posting the Contribution on social media accounts closely related to the Work, as well as using the Contribution for training purposes, such as but not limited to massive open online courses), in whole, in part or in abridged form, in each case as now known or developed in the future, including the right to grant further timelimited or permanent rights. Publisher especially has the right to permit others to use individual illustrations, tables or text quotations and may use the Contribution for advertising purposes. For the purposes of use in electronic forms, Publisher may adjust the Contribution to the respective form of use and include links (e.g. frames or inline-links) or otherwise combine it with other works and/or remove links or combinations with other works provided in the Contribution. For the avoidance of doubt, all provisions of this contract apply regardless of whether the Contribution or the Work itself constitutes a database under applicable copyright laws or not.

The copyright in the Contribution shall be vested in the name of Publisher. Author has asserted his/her right(s) to be identified as the originator of this Contribution in all editions and versions of the Work and parts thereof, published in all forms and media. Publisher may take, either in its own name or in that of Author, any necessary steps to protect the rights granted under this Agreement against infringement by third parties. It will have a copyright notice inserted into all editions of the Work and on the Contribution according to the provisions of the Universal Copyright Convention (UCC).

The parties acknowledge that there may be no basis for claim of copyright in the United States to a Contribution prepared by an officer or employee of the United States government as part of that person's official duties. If the Contribution was performed under a United States government contract, but Author is not a United States government employee, Publisher grants the United States government royalty-free permission to reproduce all or part of the Contribution and to authorise others to do so for United States government purposes. If the Contribution was prepared or published by or under the direction or control of the Crown (i.e., the constitutional monarch of the Commonwealth realm) or any Crown government 
department, the copyright in the Contribution shall, subject to any agreement with Author, belong to the Crown. If Author is an officer or employee of the United States government or of the Crown, reference will be made to this status on the signature page.

\section{$\S 2$ Rights retained by Author}

Author is permitted to self-archive a pre-print and an author's accepted manuscript version of the Contribution.

a) A pre-print is the Author's first version of the manuscript submitted to the Publisher ("Pre-Print"). Prior to acceptance for publication, Author retains the right to make a Pre-Print of the Contribution available on any of the following: his/her own personal, self- maintained website; a legally compliant, non-commercial pre-print server such as but not limited to arXiv and bioRxiv.

Once the Contribution has been published, Author should update the acknowledgement and provide a link to the definitive version on the publisher's website: "This is a pre-print of a contribution published in [insert title of book and name(s) of Editor(s)] published by [insert name of Publisher]. The final authenticated version is available online at: https://doi.org/[insert DOI]".

b) An Author's Accepted Manuscript ("AAM") is the version accepted by the Publisher for publication, but prior to copyediting and typesetting, that can be made available under the following conditions:

i. Author retains the right to make an AAM of the Contribution available on their own personal, self- maintained website immediately on acceptance,

ii. Author retains the right to make an AAM of the Contribution available for public release on any of the following, 12 months after first publication ("Embargo Period"): their employer's internal website; their institutional and/or funder repositories and all services offering organized, legally compliant central archiving, including social scientific networks. AAMs may also be deposited in such repositories immediately on acceptance, provided that they are not made publicly available until after the Embargo Period.

An acknowledgement in the following form should be included, together with a link to the published version on the publisher's website: "This is a pre-copyedited version of a contribution published in [insert title of book and name(s) of Editor(s)] published by [insert name of Publisher]. The definitive authenticated version is available online via https://doi.org/[insert DOI]".

The DOI (Digital Object Identifier) can be found at the bottom of the first page of the published Contribution.

For the avoidance of doubt Author shall not use the publisher's final published version (in pdf or html/xml format) for the purpose of the above described self-archiving.

Additionally, Author retains, in addition to uses permitted by law, the right to communicate the content of the Contribution to other research colleagues, to share the Contribution with them in manuscript form, to perform or present the Contribution or to use the content for non-commercial internal and educational purposes, provided the original source of publication is cited according to current citation standards.

\section{§ 3 Warranties}

Author agrees, at the request of Publisher, to execute all documents and do all things reasonably required by Publisher in order to confer to Publisher all rights intended to be granted under this Agreement. Author warrants that the Contribution is original except for such excerpts from copyrighted works (including illustrations, tables, animations and text quotations) as may be included with the permission of the copyright holder thereof, in which case(s) Author is required to obtain written permission to the extent necessary and to indicate the precise sources of the excerpts in the manuscript. Third Party Material (including without limitation quotations, photographs, pictures, diagrams, drawings, tables, graphs or maps, and whether reproduced from print or electronic or other sources) may only be included in the Contribution with the prior agreement of the Publisher. In this case the Author must obtain (at the Author's expense) all necessary permissions to enable the Publisher to use the Third Party Material in the Contribution and shall provide the Editor of the Work and the Publisher with: (i) copies of all such permissions, and (ii) sufficient information to enable the Publisher to make appropriate acknowledgements.

Author warrants that Author is entitled to grant the rights in accordance with Clause 1 "Rights Granted", that Author has not assigned such rights to third parties, that the Contribution has not heretofore been published in whole or in part, that the Contribution contains no libellous or defamatory statements and does not infringe on any copyright, trademark, patent, statutory right or proprietary right of others, including rights obtained through licences; and that Author will indemnify Publisher against any costs, expenses or damages for which Publisher may become liable as a result of any claim which, if true, would 
constitute a breach by Author of any of Author's representations or warranties in this Agreement. Author agrees to amend the Contribution to remove any potential obscenity, defamation, libel, malicious falsehood or otherwise unlawful part(s) identified at any time. Any such removal or alteration shall not affect the warranty and indemnity given by Author in this Agreement.

\section{§ 4 Delivery of Contribution and Publication}

Author shall deliver the Contribution to the responsible Editor of the Work on a date to be agreed upon, electronically in Microsoft Word format or in such form as may be agreed in writing with Publisher. The Contribution shall be in a form acceptable to the Publisher (acting reasonably) and in line with the instructions contained in the guidelines and Author shall provide at the same time, or earlier if the Publisher reasonably requests, any editorial, publicity or other form required by the Publisher. Publisher will undertake the publication and distribution of the Work in print and electronic form at its own expense and risk within a reasonable time after it has given notice of its acceptance of the Work to Author in writing.

\section{$\S 5$ Author's Discount for Books and Electronic Access}

Author may obtain copies of the Work for personal use at a discount of $40 \%$ off the list-price if ordered directly from Publisher. Furthermore, Author is entitled to purchase for his/her personal use (directly from Publisher) other books published by Publisher at a discount of $40 \%$ off the list price for as long as there is a contractual arrangement between Author and Publisher and subject to applicable book price regulation. Resale of such copies is not permitted.

Publisher shall provide electronic access to the electronic final published version of the Work on Publisher's Internet portal, currently known as springer.com and/or palgrave.com, to Author, provided Author has included his/her email address in the manuscript of the Work. Furthermore, Author has the right to download and disseminate single contributions from the electronic final published version of the Work for his/her private and professional non-commercial research and classroom use (e.g. sharing the contribution by mail or in hard copy form with research colleagues for their professional non-commercial research and classroom use, or to use it for presentations or handouts for students). Author is also entitled to use single contributions for the further development of his/her scientific career (e.g. by copying and attaching contributions to an electronic or hard copy job or grant application).

When Author is more than one person each of the co-authors may share single contributions of the Work with other scientists or research colleagues as described above. In each case, Publisher grants the rights to Author under this clause provided that Author has obtained the prior consent of any co-author(s) of the respective contribution.

\section{$\S 6$ Termination}

Either party shall be entitled to terminate this Agreement forthwith by notice in writing to the other party if the other party commits a material breach of the terms of the Agreement which cannot be remedied or, if such breach can be remedied, fails to remedy such breach within 28 days of being given written notice to do so.

On termination of this Agreement in accordance with its terms, all rights and obligations of Publisher and Author under this Agreement will cease immediately, except that any terms of this Agreement that expressly or by implication survive termination of this Agreement shall remain in full force and effect.

\section{§ 7 Governing Law and Jurisdiction}

If any difference shall arise between Author and Publisher concerning the meaning of this Agreement or the rights and liabilities of the parties, the parties shall engage in good faith discussions to attempt to seek a mutually satisfactory resolution of the dispute. This agreement shall be governed by, and shall be construed in accordance with, the laws of Switzerland. The courts of Zug, Switzerland shall have the exclusive jurisdiction. 
Corresponding Author signs for and accepts responsibility for releasing this material on behalf of any and all CoAuthors.

Signature of Corresponding Author:

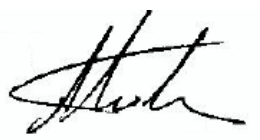

Date:

$09 / 11 / 2018$

$\square$ I'm an employee of the US Government and transfer the rights to the extent transferable (Title $17 \S 105$ U.S.C. applies)

$\square$ I'm an employee of the Crown and copyright on the Contribution belongs to the Crown

For internal use only:

Order Number: 86989872

GPU/PD/PS: 5/50/559

Legal Entity Number: 1128 Springer International Publishing AG

Springer-C-CTP-05/2018 